$\underline{\text { Review Article }}$

\title{
ETIOLOGICAL FACTORS FOR THE DEVELOPMENT OF LUNG CANCER IN NON-SMOKERS: AN OVERVIEW
}

\author{
MUHAS C. ${ }^{1}$, P. R. ANAND VIJAYA KUMAR2*, RAJA D. ${ }^{1}$ \\ 1Department of Pharmacy Practice, JSS College of Pharmacy, Ooty 643001, Tamil Nadu, India, 2Department of Pharmacology, JSS College of \\ Pharmacy, Ooty 643001, Tamil Nadu, India \\ Email: ootyanand2004@gmail.com
}

Received: 10 Oct 2018 Revised and Accepted: 13 Nov 2018

\begin{abstract}
Lung cancer is the most frequent malignant tumour with the highest mortality rate around the world, leading to greater than a million deaths annually. The number of deaths due to lung cancer is expected to increase to ten million deaths per year in 2030 . The major risk factor for the development of lung cancer is cigarette smoking but relatively high rates of lung cancer occur among non-smoking women and $10-25 \%$ of lung cancer observed in never smokers. The lung cancer deaths occur in never smokers have been estimated to be the 7th leading cause of cancer mortality. This article mainly discusses the important etiological factors of lung cancer in never smokers such as the environmental factors, occupational exposure, history of lung disease, family history and genetic factors, unbalanced diet and high consumption of saturated fat, radiation exposure, socioeconomic status, and infections. Gender, obesity and metabolic syndrome, race and ethnicity and interstitial lung diseases also have effects on the development of lung cancer in never smokers.
\end{abstract}

Keywords: Lung Cancer, Non-smokers, Environmental factors, Occupational factors

(C) 2019 The Authors. Published by Innovare Academic Sciences Pvt Ltd. This is an open access article under the CC BY license (http://creativecommons.org/licenses/by/4.0/) DOI: http://dx.doi.org/10.22159/ijpps.2019v11i1.30247

\section{INTRODUCTION}

Cancer is considered as one of the major distressing disease worldwide and out of many cancers, lung cancer is one of the serious health problem $[1,2]$. In the early 1900 s lung cancer was a rare disease, but now it's becoming the most common cause of cancer death worldwide [3]. In the year 2012, about 1.8 million new cases of lung cancer were diagnosed, which accounted for $12.9 \%$ of the world's total cancer incidence [4]. Lung cancer considered as the most fatal forms of cancer because lack of proper diagnosis and lack of effective treatments and it accounts for more deaths than any other cancer types [5, 6]. The GLOBOCAN 2018 estimated that in both sexes combined, lung cancer is the most commonly diagnosed cancer $(11.6 \%$ of the total cases) and the leading cause of cancer death $(18.4 \%$ of the total cancer deaths), closely followed by female breast cancer (11.6\%), prostate cancer $(7.1 \%)$, and colorectal cancer $(6.1 \%)$ for incidence and colorectal cancer $(9.2 \%)$ stomach cancer $(8.2 \%)$, and liver cancer $(8.2 \%)$ for mortality. Lung cancer is the leading cause of cancer death among males followed by prostate and colorectal cancer (for incidence) and liver and stomach cancer (for mortality) [7]. Even though in some countries the declining trends in the incidence of lung cancer was reported, it will continue to be a major cause of death through the world [8]. The number of deaths due to lung cancer is expected to increase to ten million deaths per year in 2030 [9]. Lung cancer is mainly found malignancy in males, and is becoming increasingly common among female gender [10]. Lung cancer incidence and mortality rate among male is 3 times higher than in females [11].

In India also it is a one of the major health care problem [12]. It is commonest in men in India accounting for $11.3 \%$ of all new cancers and also is the most common cause of cancer death $(13.7 \%)$. In different parts of India, the various demographic profiles such as age, sex, stage, history, and even the molecular epidemiology varies considerably. However, as compared to many western countries the overall incidence is much lower [13]

Lung cancer mainly originates from the basal epithelial cells and is mainly classified into two types, non-small cell lung cancer (NSCLC) and small cell lung cancer (SCLC). Among these NSCLC is more common and which accounts for approximately 85\% of lung cancer cases, with adenocarcinoma accounting for $40 \%$ of the total and 5-
$10 \%$ is large cell carcinoma $[5,14]$. Lung cancer has a low survival rate (with an overall 5-year survival rate of $10 \%$ to $15 \%$ ) because most patients are diagnosed at a late stages and have a poor prognosis [15]

The major risk factor for the development of lung cancer is cigarette smoking but relatively high rates of lung cancer occur among nonsmoking women and $10-25 \%$ of lung cancer observed in never smokers $[2,16,17]$. The lung cancer deaths occur in never smokers have been estimated to be the 7th leading cause of cancer mortality [18]. In an epidemiological view, lung cancer in never smokers is now considered as a distinct disease entity. In India, increase in the number of lung cancer cases among never smokers is evident [19]. The geographic variation affects the incidence of lung cancer in never smokers [20].

The adenocarcinoma has surpassed squamous cell carcinoma as the most histologic variant of lung cancer in western countries and most of the Asian countries. The main reason for this shift is the changed smoking pattern and increasing incidence of lung cancer in females and never smokers [6].

As we found that lung cancer in never smokers is a distinct disease entity and that is more frequent in women than in men and in certain geographical regions than in other (Asia $>$ North America>Europe). The environmental factors such as outdoor and indoor air pollution and occupational exposure were an important risk factor for the development of lung cancer in these population [21]. The other major risk factors considered important for never smokers include other environmental exposure, history of lung disease, family history and genetic factors, unbalanced diet and high consumption of saturated fat, radiation exposure, socioeconomic status, and infections. Gender, obesity and metabolic syndrome, race and ethnicity and interstitial lung diseases also have effects on the development of lung cancer in never smokers [2, 4, 19, 22, 23].

\section{Environmental factors}

Even though tobacco smoking is the major cause for the development of lung cancer, the environmental cause of lung cancer, including air pollution have long been a concern. There is a clear epidemiological evidence that suggests a considerable association between air pollution and lung cancer, but the rate is small as compared with cigarette smoking [2]. It is reported that in males 
who had no family history of cancer and who were never smokers, but exposed to high environmental pollutants, the odds ratio was 6.8 for the risk of developing lung cancer [19].

The contribution of air pollution exposure estimated to 62,000 lung cancer death per year worldwide [2]. Air pollution is responsible for $5-7 \%$ of lung cancer in non-smokers [19]. So far, air pollution studies that have examined the relationship with lung cancer have mainly been one in Europe and North America, although in recent years several studies also carried out on other continents and the results also show the association between air pollution and lung cancer risk [24]. In developing countries like India, the studies that found the relation between lung cancer and air pollution is very less, and therefore opportunities to strengthen the scientific evidence on air pollution and lung cancer should be pursued.

Indoor air pollution mainly resulting from the incomplete combustion of solid fuels such as wood, coal, agricultural waste, charcoal and animal dung for cooking and or heating is major global public health concern [25]. Indoor air pollution consists of complex mixture of pollutants including particulate matter, sulphur oxides, nitrogen oxides, carbon monoxide, polycyclic aromatic hydrocarbons, formaldehyde, and dioxins, to name few [26]. The use of indoor combustion products is extremely high in Africa and South East Asia when compared to the developed regions such as the US and European countries [19]. The non-smoking women chronically exposed to cooking fumes generated from burning wood or frying fat at high temperatures in China and these women appears to be at increased risk of lung cancer, especially adenocarcinoma [27].

A significant relation between lung cancer and using solid fuel for cooking was established by a case-control study that conducted in Japan (RR=1.8, 95\% CI: 1.1-2.9). Similar studies were also conducted in the Northern Provinces of South Africa, results were also same and the OR of lung cancer among using wood or coal as main fuel was 1.4 (95\% CI: 0.6-3.2) [2]. A study carried in Guangzhou and in other Chinese cities implied an association between indoor air pollution and the incidence of lung cancer deaths in females [28]. The data available from other regions of the world that supporting a similar effect of exposure to cooking and heating-derived indoor air pollution is limited [2]. The findings of Ole Raaschou-Nielsen and colleagues from individual data from 17 European cohorts presented in the Lancet Oncology showed that exposure to particulate matter air pollution increased the risk of lung cancer particularly adenocarcinoma [24].

Outdoor air pollution increases the risk of lung cancer [20]. The vehicle exhaust, heating systems, and industrial burning waste are the main sources of outdoor air pollution [4]. The quality of air decrease by the release of these industrial fumes and vehicular exhausts and many studies have reported the association of lung cancer risk and air quality [19]. In a study that conducted by Raaschou-Nielsen et al. found that non-smokers and residents near heavy traffic roads are at a high risk of air pollution associated with lung cancer. Moreover, they reported that nitrogen oxide and nitrogen dioxide emitted from the vehicle engine exhaust are the major etiological factor for the development of lung cancer in urban population [29].

Nyberg and colleagues conducted a case-control study in Sweden and found a relative risk for lung cancer of 1.44 for persons exposed to more than $29.3 \mu \mathrm{g} / \mathrm{m} 3$ of nitric oxide (as a measure of traffic air pollutant) over 21 to 30 y compared with exposures to lower than 12.8 $\mu \mathrm{g} / \mathrm{m} 3$ of nitric oxide [30]. The another important component of air pollution is considered as diesel exhaust and one study implied a strong support especially in persons in the trucking industry that occupational exposure to diesel exhaust is associated with an approximately $30 \%$ to $50 \%$ increase in the relative risk of lung cancer [20]. Some studies reported that exposure to sulphur dioxide in the paper and pulp industry increases the chances of lung cancer [31].

Environmental tobacco smoke (ETS); over the last years, the role of ETS in the causation of lung cancer has been repeatedly evaluated [2]. Today, the association between ETS and lung cancer has been largely reported [21]. A study conducted by Elisabetta Rapiti et al. in Chandigarh, India and this study suggests that ETS exposure may be a strong risk factor for lung cancer [32]. A large number of epidemiologic studies on the risk for lung cancer in non-smokers is conducted and the summary analysis of these studies found an excess risk for lung cancer of $24 \%$ in non-smokers who lived with a smoker [33].

In a study that conducted in non-smoking women found that tobacco use by the spouse was associated with a $30 \%$ excess risk for all types of lung cancer [33]. International agency for research on cancer (IARC) concluded from the review of numerous studies that involuntary smoking is carcinogenic to humans, with an increased risk of $20 \%$ for women and of $30 \%$ of men among never smokers who are exposed to second-hand smoke (i.e., environmental tobacco smoke) from their spouse [34]. In a meta-analysis of 55 recent studies of spousal smoking on the lung cancer risk demonstrated that the non-smoking spouse showed a pooled relative risk of 1.27 (95\% CI: 1.17-1.37) with risk increasing monotonically with increasing exposure [18].

\section{Occupational factors}

Lung cancer is considered as the most occupationally acquired malignancy among the various types of cancers [19]. Worldwide, due to occupational exposure to the carcinogen, there are estimated 152,000 deaths from lung cancer and approximately 1.6 million disability-adjusted life years from lung cancer [20]. There are 12 occupational factors as being identified as carcinogenic to human lung by international agency for research on cancer (IARC) and these include aluminium production, arsenic, asbestos, bis-chloromethyl ether, beryllium, cadmium, hexavalent chromium, coke and coal gasification fumes, crystalline silica, nickel, radon and soot [4]. The important factors are explained below.

Asbestos is a well-established carcinogen among all occupational cancer causing agents and exposure to this compound at high levels can cause mesothelioma and lung cancer. Asbestos present in 2 forms: Serpentine (i.e., chrysotile) and amphibole (i.e., actinolite, amosite, anthophyllate, crocidolite, and tremolite) [35]. The risk that associated with asbestos exposure for the development of lung cancer is dose dependent but varied with the type of asbestos fibre exposure. The risk for lung cancer seems lower for workers exposed to chrysotile fibres than for those exposed to amphibole fibres, after adjusting for similar exposure levels. Recent studies have shown that asbestos exposure was associated with a relative risk for lung cancer of 3.5 after adjusting for age, smoking and vitamin intake. The observed carcinogenic effect of asbestosis clearly potentiated by tobacco smoking, however, the magnitude of this combined effect is not clear. One study found that the relative risk for lung cancer with cigarette smoking alone 11 fold, with asbestos exposure alone, is 6 fold, but with exposure to both asbestos and cigarette smoke, the increase may be as high as 59-fold [20].

Arsenic is said to be both an occupational and environmental lung carcinogen [36]. In never smokers, arsenic exposure is strongly associated with lung cancer and in these individual's distinct mutational profile was observed [19]. Occupational exposures of arsenic that occurs primarily among workers whom breath dust from lead, gold, and copper ore mines and smelters [36]. The fairly constant exposure to arsenic via inhalation increases lung cancer risk is found by IARC from various cohort and nested case-control studies [37]. Clement-Duchene et al. found that gender was an important element of these occupational risk factor, $48.6 \%$ of men were exposed to occupational carcinogens versus $9.4 \%$ of women $(\mathrm{P}<0.0005)$ [38].

Chromium compounds; Hexavalent chromium (chromium VI) compounds that are produced primarily from industrial processes are classified as Group 1 lung carcinogens. From a review of more than 25 cohort studies, the IARC concluded that there was sufficient evidence in humans for the lung carcinogenicity of chromium (VI) compounds especially for highly exposed workers in the chromate production, chromate pigment production, and chromium plating industries [36].

Nickel compounds; nickel is a naturally occurring silvery white metal and the potential for low-level atmospheric nickel exposure 
occurs from natural (e. g., windblown dust, volcanoes, and wildfires) and anthropogenic activities (e. g., mining, refining, smelting, manufacture of nickel-containing alloys and stainless steel). After a detailed review of pertinent epidemiologic studies, The IARC working group found that there is strong evidence for the carcinogenicity of nickel compounds [36].

Table 1: Group 1 IARC carcinogens with sufficient evidence of causing lung cancer in humans and primary type of exposure

\begin{tabular}{|c|c|c|c|}
\hline \multicolumn{2}{|c|}{ Agent } & Primary exposure type & References \\
\hline \multicolumn{4}{|c|}{ Ionizing Radiation-all types } \\
\hline$>$ & Alpha-particle emitters & E, 0 & {$[44]$} \\
\hline - & Radon-222 and its decay products & E, $\mathrm{O}$ & [27] \\
\hline - & Plutonium-239 & 0 & [36] \\
\hline$>$ & X-radiation, gamma-radiation & E, $\mathrm{O}$ & [36] \\
\hline \multicolumn{4}{|c|}{ Chemicals and mixtures } \\
\hline$>$ & Bis (Chloromethyl) ether; Chloromethyl methyl ether & 0 & [43] \\
\hline$>$ & Coal-tar pitch & 0 & [41] \\
\hline$>$ & Soot & 0 & [41], [42] \\
\hline$>$ & Sulphur mustard & 0 & [43] \\
\hline$>$ & Diesel exhausts & E, $\mathrm{O}$ & {$[40]$} \\
\hline \multicolumn{4}{|c|}{ Occupations } \\
\hline$>$ & Aluminium Production & 0 & [37] \\
\hline$>$ & Coal gasification & 0 & [36] \\
\hline$>$ & Coke production & 0 & [36] \\
\hline$>$ & Iron and steel founding & 0 & [37] \\
\hline$>$ & Painting & 0 & [36] \\
\hline$>$ & Rubber production industry & 0 & [39] \\
\hline \multicolumn{4}{|c|}{ 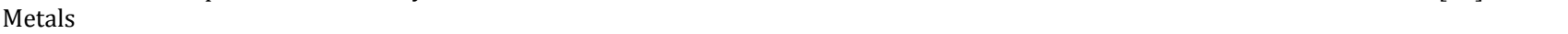 } \\
\hline$>$ & Arsenic and inorganic arsenic compounds & E, $\mathrm{O}$ & [19], [37] \\
\hline$>$ & Cadmium and cadmium compounds & 0 & [36] \\
\hline$>$ & Beryllium and beryllium compounds & 0 & {$[04]$} \\
\hline$>$ & Chromium (VI) compounds & 0 & {$[02],[36]$} \\
\hline$>$ & Nickel compounds & 0 & [36] \\
\hline \multicolumn{4}{|c|}{ Dust and fibres } \\
\hline$>$ & Asbestos (all forms) & E, $\mathrm{O}$ & [35] \\
\hline$>$ & Silica dust, crystalline & E, $\mathrm{O}$ & [39] \\
\hline \multicolumn{4}{|c|}{ Personal habits } \\
\hline$>$ & Coal, indoor emission from household combustion & E & [04], [26] \\
\hline$>$ & Tobacco smoke, second hand & E, O & [21], [33] \\
\hline
\end{tabular}

Abbreviations: E, environmental exposure; 0, Occupational exposure

Rubber manufacturing industry in Rubber manufacturing industry, Rubber production workers are exposed to fumes with a complex chemical composition produced during the heating, curing of rubber compounds and also in vulcanizing process [36]. Many retrospective cohort mortality studies reported that increased lung cancer risks among rubber workers involved with mixing and milling, vulcanization and in cohorts of workers exposed to high concentrations of fumes and/or solvents and based on this the IARC workgroup concluded that there was sufficient evidence in humans for the carcinogenicity of occupational exposures in the rubber manufacturing industry [39].

Painting various paints consist of hundreds of hazardous chemicals including dichloromethane, di isocyanates, amines, esters, chromates, nickel etc. and the painters continue to have the potential for exposure to these chemicals. In between the year 1951 and 2010, more than 50 epidemiologic studies (i.e., cohort and case-control) were published and that overall demonstrates a relatively consistent increased risk of developing lung cancer for painters [36].

Diesel engine exhaust is both environmental and occupational factor for the development of lung cancer. The occupations that are known to have increased risk of exposure to diesel exhaust include underground miners, truck and bus drivers, toll booth attendants, construction workers etc. [40]. After the review of available literature, the IARC workgroup added diesel engine exhaust as a Group I carcinogen on June 12, 2012 [36].

Soot is the carbonaceous by-product material which produced by the incomplete conversion of fossil fuel or other carbon-containing material (e. g., paper, plastics) to combustion products (e. g., water vapour, CO2). The main constituents of soot are up to $60 \%$ carbon, inorganic material and a soluble fraction consisting primarily of PAHs. The higher potential for soot exposure is mainly occurs from the occupations like chimney sweeps, fire-fighters, brick masons and helpers; and others that require work near where organic matter is burned [41]. A standardized incidence ratio of 1.49 (95\% CI: 1.3-1.7) for lung cancer for chimney sweeps reported from a study that published in 2009 from Denmark, Finland, Norway, and Sweden, a total of 212 incident lung cancer were observed in chimney sweeps [42].

Coal-tar pitch is a solid residue that produced from the distillation of coal tars. The major part of coal-tar consists of 3-membered to 7membered polycyclic aromatic hydrocarbons (PAHs), as well as their methylated derivative with lower concentrations of phenolic compounds and nitrogen bases. From various epidemiologic studies of road pavers and roofers, IARC working groups determined that there was sufficient evidence to support the carcinogenicity of coal-tar pitch [36].

Sulphur mustard in the military sector is called mustard gas, is primarily a chemical warfare agent. The exposure to sulphur mustard can also occur during its storage and destruction or from inadvertent exposure near dumping areas or areas where contamination may have occurred in the past (e. g., military installations, demolition of old buildings). The carcinogenicity of sulphur mustard is firmly established from findings of numerous studies performed between 1950 and 2000 detailing the adverse effects of short-term battlefield exposure and prolonged exposure in chemical factories [43].

Bis (chloromethyl) ether (BCME); technical-grade chloromethyl methyl Ether (CMME); The IARC states that BCME is among the most potent human carcinogen known based on numerous studies of exposed workers. Statistically significant increases in the relative risks for lung cancer for exposure to BCME was reported from six epidemiologic studies performed in 1970 [36]. Manufacturing of BCME and technical-grade CMME were conducted widely before 1976 in the US, but the use of these chemicals has been reduced substantially in the United States because of their lung carcinogenicity [43]. 
Other Occupational carcinogens the occupations related with aluminium production, coke production, coal gasification, iron and steel founding also causes exposure to these carcinogens and may leading to the development of lung cancer. The exposure to metals like beryllium and beryllium compound, cadmium and cadmium compounds may also lead to the development of lung cancer [36].

\section{Radiation}

Radiation plays an important role in the development of lung cancer [44]. The exposure to high doses of radiation is associated with lung cancer is reported by various epidemiologic studies. However, the development of lung cancer with the exposure to low dose radiation is still unclear [45]. All types of ionizing radiation cause carcinogenesis in humans and these are coming under IARC Group 1 carcinogens [46]. The low linear energy transfer radiation (e. g., $x-$ rays, gamma rays) and high linear energy transfer radiation (e. g., neutrons, radon) are relevant to lung cancer) [45].

Radon is an inert gas and that is produced naturally from radium in the decay series of uranium [4]. Radon-222 decay products and Plutonium-239emits alpha-particles and these radionuclides are classified as Group 1 carcinogen by IARC [36]. Radon-222 and its decay products include polonium 218 and polonium 214 are the oldest known occupational carcinogens. After inhalation of these radon decay products, subsequent emission of alpha particle occurs in the lungs which may cause damage to cells and genetic material $[20,36]$. Apart from outdoors, radon can also present in underground structures, such as mines, as well as built environments, such as homes, offices, and schools [47]. The possible risk for lung cancer in the general population associated with radon exposure has been a concern in recent years [20].

About 20,000 lung cancer deaths occur in the United States each year which are radon-related. The chronic exposure to radon contributes to the occurrence of lung cancer is found by three cohort studies conducted in Europe, North America, and China. The relative risk of lung cancer in the observed radon concentrations greater than per 100 $\mathrm{Bq} / \mathrm{m} 3$ was $8 \%$ (95\% CI: $3-6 \%$ ), $11 \%$ (95\% CI: $0-28 \%$ ), and $13 \%$ (95\% CI: 1-36\%), respectively [4]. A meta-analysis suggests a linear exposure-response relationship among smokers and in case of individual studies related with radon yield inconsistent results. A meta-analysis of 13 European studies is conducted to examine the impact of residential radon gas exposure on lung cancer risk and the results showed a greater absolute hazard to cigarette smokers and recent ex-smokers than to lifelong non-smokers [27].

\section{$\mathrm{X}$-rays and gamma rays}

Based primarily on the findings of the life span studies (LSS) of atomic bomb survivors in Hiroshima and Nagasaki, Japan; the IARC classified X-rays and gamma rays as Group 1 lung carcinogens in 2000. Based primarily on findings from the LSS cohort as well as with supplemental findings from populations exposed to medical procedures, the recent 2012 IARC monograph continues to update $\mathrm{x}$ ray and $\gamma$-ray cancer risk estimate [36].

\section{Family history}

As we know that the major cause of lung cancer is smoking and air pollution, however, genetic factors also contribute to the development of lung cancer which is demonstrated by numerous studies. Several factors influence the familial aggregation of lung cancer which includes similar lifestyles (e. g., smoking habit and diet) and similar environment so (e. g., indoor and outdoor air pollution) [31].

Forty years ago, the first evidence of familial aggregation of lung cancer is reported from an epidemiologic study conducted by Tokuhata and Lilienfeld [48]. Several studies reported the familial aggregation and increased familial risk for lung cancer, which indirectly reporting that genetic factors contribute to susceptibility to lung cancer [49]. In never smokers, the degree of relation between family history and development of lung cancer has not been clearly established [50]. To address this issue, a pooled analysis that included 24 case-control studies is conducted by the International Lung Cancer Consortium, after adjustment for smoking and other potential confounders, 1.51 -fold increase in the risk of lung cancer occurs among individuals with a first-degree relative with lung cancer [51]. The risk of the disease is increased about two to five times in persons with a family history of lung cancer is reported by several epidemiologic studies, even after controlling for personal smoking [52]. There is 2-fold increased risk for lung cancer in persons with a family history of lung cancer is reported by a metaanalysis involving 32 studies and this increased risk is also present with non-smokers [20]. In several studies, for both smokers and never smokers, family history of lung cancer has been considered as a factor for increased risk of non-small cell lung cancer (NSCLC) [50].

\section{Previous lung diseases}

Previous lung diseases are a particular set of risk factors that may play a major role in lung cancer development. The important previous lung diseases are the chronic obstructive pulmonary disease (COPD) (including emphysema and bronchitis), pneumonia, and tuberculosis causes inflammation of lung tissues and this has been suggested to increase the risk of lung cancer. These diseases may develop lung cancer through common aetiologies and/or exposures and may act as the catalyst in the development of lung neoplasms $[53,54]$. Increase in risk of lung cancer is also associated with other interstitial lung diseases including pulmonary fibrosis, sarcoidosis, systemic sclerosis [55]. A recent article found that $13 \%$ of female lung cancers among lifetime never smokers and 16\% among former smokers may be attributable to previous lung diseases [52].

Cigarette smoking is the major etiological factor for developing COPD and lung cancer and there is increasing evidence linking the two diseases beyond a common etiological factor [5]. More recently many studies in large cohorts have found that COPD is significantly related with an increased risk for lung cancer, especially in men [20]. COPD is also considered as risk factor for the development of lung cancer like other factors including exposure to ETS and exposure to asbestos [56] COPD is considered as an independent risk factor for the development of lung carcinoma, particularly for squamous cell carcinoma and in smokers with airflow obstruction, lung cancer is up to five times more likely to occur than those with normal lung function [5].

A systematic review and meta-analysis on 39 studies are conducted by Darren R Brenner et al. in 2011 and suggests that COPD, emphysema, and chronic bronchitis are associated with a significantly increased lung cancer risk [57]. The association of COPD, emphysema, and chronic bronchitis with the increased risk of lung cancer is verified by a case-control study from China. The processes that seen in COPD and lung cancer are common which include premature aging in the lungs, genetic predisposition to either disease or common pathogenic factors, activation of intracellular pathways or epigenetics and this suggests high prevalence of lung cancer in COPD patients [58]. A potential method enables early detection of lung cancer and thereby to improve outcomes is screening of COPD patients for the development of cancer, for example through CT scans. The relationship between asthma and lung cancer was still uncertain [58].

The link of tuberculosis infection and subsequent lung cancer risk is examining by authors of a systematic review of 37 case-control and 4 cohort studies and concluded that at least for adenocarcinoma, there is a direct relation exists between tuberculosis infection and subsequent lung cancer risk [18]. The Previous diagnosis of TB and pneumonia is related with increased lung cancer risk across studies independent of smoking is suggested by Darren R Brenner et al. in 2011 [57]. The relative risk remained significant for those with a history of pneumonia $[\mathrm{RR}=1.90(95 \% \mathrm{CI}=1.10-1.69)]$ or Tuberculosis $[\mathrm{RR}=1.90$ (95\% CI=1.45-2.50)], when limited to never smokers [21].

\section{Race and ethnicity}

Race often has a strong socioeconomic association and is a complex variable. In the United States, the incidence of lung cancer is substantially higher among blacks and Native Hawaiians and other Polynesians and lower among Japanese Americans and Hispanics than among whites is showed by Menck. Among the different ethnic and racial groups, the pattern of cigarette smoking is varied and this is mainly attributed to the difference in the development of lung cancer when considering the race and ethnicity [59]. 
In a case-control study, Cote and colleagues showed that first degree relatives of white persons with early onset lung cancer have a lower risk for lung cancer than their black counterparts $(17.1 \%$ vs $25 \%$ respectively) [60]. The increasing cigarette smoking exposure further amplified these cumulative differences in risk for lung cancer among blacks and whites. The mechanisms behind in these observed racial or ethnic variations in risk for lung cancer is not clearly identified [20].

\section{Age}

A number of papers reported the strong influence of age on lung cancer among never smokers. As a proxy for duration of exposure to various lung carcinogens like cigarette smoke, radon gas etc., age is empirically an important predictor of lung cancer in both smokers and non-smokers, and arguably age is considered as the most important risk factor among never smokers [18]. The median age of onset for lung cancer is $66 \mathrm{y}$ old and chances of developing lung cancer increase with age [5].

A controversy has been existing in the age at which the patients are diagnosed with lung cancer in non-smokers. The average age for developing lung cancer in never smokers is $59 \mathrm{y}$ [19]. Specifically, $31.1 \%$ of patients with lung cancer are between 65 and $74 \mathrm{y}, 29 \%$ between 75 and $84 \mathrm{y}$, an $8.3 \%$ are $85 \mathrm{y}$ old and older. The mean age at the time of diagnosis is found to be over $70 \mathrm{y}$. The smoking prevalence with persons aged 18 to $24 \mathrm{y}$ is $21.4 \%, 25$ to $44 \mathrm{y}$ is $23.7 \%$, 45 to $64 \mathrm{y}$ is $22.6 \%$ and prevalence is $9.3 \%$ among persons aged $65 \mathrm{y}$ and older. From this, we can understand that the smoking prevalence is lowest among persons aged $65 \mathrm{y}$ and older, but more than $65 \%$ of patients with lung cancer are older than 65 . In an elderly population, the smoking prevalence is lower and there is higher cancer rate, this difference likely reflects heavy smoking history in current elderly population [20].

\section{Gender}

Among never smokers, the lung cancer incidence rate is higher in women than men [3]. Wynder and Graham noted in an early study of tobacco smoking that a higher percentage of cancers in non-smokers occurred in women than men [61]. The hormones played a major role in the development of lung cancer in non-smoking women. In cancerous lung tissue, the oestrogen receptors (ER) $\alpha$ and $\beta$ are expressed more frequently than in normal lung tissue. Conversely, progesterone receptors are less frequently present in cancerous tissue [21]. In the late 1980s, lung cancer surpassed breast cancer as the leading cause of cancer deaths in women, and now almost twice as many women die of lung cancer than breast cancer [62].

Compared with men, there are different clinical features of lung cancer in women, such as the percentage of adenocarcinoma increases among never smokers, the greater prevalence of epidermal growth factor receptor gene (EGFR) mutation in adenocarcinomas among never smokers and better prognosis [3].

\section{Diet}

It has been suggested that some dietary factors are responsible for developing approximately $30 \%$ of all cancers [20]. As we understand that the major causative factor for the development of lung cancer is tobacco smoking, which is the reason for more than $85 \%$ of lung cancer; however, occupation and diet are also important determinants for this disease [63]. There are different studies that reported that certain dietary factors may be protective for, and others may increase the risk of lung cancer [64].

After many years of research on diet and lung cancer, many specific micronutrients such as retinol and beta-carotene thought to have anti-carcinogenic activity, have been found. In fruits and vegetables, most of the micronutrients are commonly present [4]. A large cohort study in the Netherlands found that a diet rich in vegetables and fruits has been linked to decreased lung cancer incidence, with the protective effects are stronger in current smokers than in older smokers [20]. In China, report from many case-control studies have shown that vegetable intake is providing a protective effect on lung cancer and pumpkins and onions had the most consistent protective effect [64]. Green vegetables and bananas providing a protective effect on the development of lung cancer is reported from another study that conducted by Sankaranarayanan [65]. The intake of vegetables described as cruciferous, which are rich in isothiocyanates, such as broccoli and cabbage, has some protective effect against the development of lung cancer [66]. In another study, it has also been suggested that consuming fruits or vegetables raw rather than cooked is associated with a further reduction in risk for lung cancer because carotenoids which present in that vegetables or fruits can be destroyed with cooking [67]. Epidemiological studies found that use of tomatoes and its products is related with reduced risk of cancer development [68]. Overall, it has been suggested that low or no consumption of fruits or vegetables have been related with up to 3 -fold risk for lung cancer [20].

On the other hand, many studies reported that animal food products and dairy products have a predisposing effect on lung cancer [64]. The dietary items that have been suggested as increasing the risk for lung cancer include red meat, dairy products, saturated fats, and lipids [20]. In a case-control study that conducted by Mostafa Hosseini et al. in 2014, found that bread, beef, liver, dairy products, vegetable ghee, and animal ghee could be possible predisposing factors of the development of lung cancer [69]. In an another study reported that, increased risk of squamous cell lung cancer is significantly associated with the consumption of food products like red meat, beef and fried meet [65]. The risk of lung cancer is increased by the consumption of meat, due to the presence of mutagenic substances produced mainly during the cooking process [70]. In Kerala, South Indian state, a marked increase in risk was observed for beef consumption (OR-12.5) [65]. Many studies are also reported that low serum concentrations of antioxidants, such as vitamins $\mathrm{A}, \mathrm{C}$, and $\mathrm{E}$, have been related with the development of lung cancer $[20,71]$.

\section{Socioeconomic status}

A person living in hygiene conditions, consuming a proper diet, and access to education and health care depends on the financial status of an individual. The incidence and prognosis of lung cancer are strongly linked with the socioeconomic status [19]. A meta-analysis is performed in 2009 and the results of this analysis appear to confirm the relation of low education and revenue levels with an increased risk of lung cancer (after adjustment of smoking, OR=1.65 [95\% CI-1.19-2.25]). Furthermore, for poor disease outcome and poor access to health care, a low socioeconomic status has also been considered as a major factor [21].

\section{Infections}

There is well-established data are available for the association between infection, inflammation and cancer risk [21]. The production of pro inflammatory molecules such as reactive oxidative species and growth factors are induced by an infection. The relation between infections and the risk of a variety of cancers, including lung cancer is well established and ample pieces of evidence are available [19]. The roles of several pathogens have been studied in case of lung cancer [21]. The risk for lung cancer is suspected to increase by the history of infectious diseases, such as tuberculosis (TB), human immunodeficiency virus (HIV), epstein-barr virus (EBV), and human papilloma virus (HPV), and infections with Chlamydia pneumonia, Microsporumcanis, and Helicobacter pylori [72]. The other viruses like human cytomegalo virus, Simian virus 40 , BK virus, JC virus, and measles virus are suggested as causative factor for the development of lung cancer; however, the results have remained inconclusive [20].

In never smokers, Human Papilloma Virus (HPV) is considered as a well-known carcinogen in a particularly virulent form for the development of lung cancer [21]. A Taiwanese study that conducted on 141 lung cancer patients (versus control) in 2001, the reports shown that HPV types 16 and 18 were more frequently present in tumours lung tissue than in tissue of the healthy lung. In never smoker's patients aged more than $60 \mathrm{y}$, the frequency at which HPV was found in tumours appeared to be higher. A potential role for human papillomavirus (HPV), known to cause carcinoma in other tissues is suggested by many studies recently [20]. The hypothesis that HIV infection increases lung cancer risk is supported by the 
review of existing data, with substantial evidence that this effect is independent of smoking [73].

The association of pulmonary tuberculosis with lung cancer is reported by some studies. Increase risk for lung cancer with tuberculosis patients is reported by Taiwanese cohort study. Studies continue to report that infection with Mycobacterium tuberculosis is associated with a risk of lung cancer $[\mathrm{RR}=1.74(95 \% \mathrm{CI}=1.48-2.03)]$, independently of smoking status [21]. One study showed that, female never-smokers with TB had approximately an eight-fold increase in lung cancer risk than those without TB; but not in smokers [74]. Especially in cigarette smokeexposed individuals, it has also been suggested that Chlamydia pneumonia, a common cause of acute respiratory infection, might be involved in lung cancer carcinogenesis [75].

\section{CONCLUSION}

Lung cancer considered as the most fatal forms of cancer because lack of proper diagnosis and lack of effective treatments and it accounts for more deaths than any other cancer types. Even though tobacco smoking is the major cause for the development of lung cancer, there is alarming rise in incidence of lung cancer among nonsmokers and this indicated that there could be other risk factors besides smoking. We understood that the other risk factors were also played their role in the development of lung cancer. We revealed that exposure to ETS, Various chemicals from occupation sites, air pollution can increase the risk for getting lung cancer. The dietary agents, previous lung disease, various infections, family history etc. can also act as various etiological factors for developing lung cancer. These findings can assist us in preventing lung cancer from the etiologic level.

\section{AUTHORS CONTRIBUTIONS}

All the author have contributed equally

\section{CONFLICT OF INTERESTS}

\section{Declared none}

\section{REFERANCES}

1. Anitha P, Bhargavi J, Sravani J, Aruna B, Ramkanth S. Recent progress of dendrimers in drug delivery for cancer therapy. Int J Appl Pharm 2018;10:34-42.

2. Wang S, Zhao Y. Air pollution and lung cancer. Elsevier 2011. p. 26-38.

3. Alberg A, Wallace K, Silvestri G, Brock M. Invited commentary: the aetiology of lung cancer in men compared with women. Am J Epidemiol 2013;177:613-6.

4. Yousheng M, Ding Y, Jie H, Mark JK. Epidemiology of lung cancer. Surg Oncol Clin N Am 2016;25:439-45.

5. Durham AL, Adcock IM. The relationship between COPD and lung cancer. Lung Cancer 2015;90:121-7.

6. Anita N, Rakesh P, Vijay MP, Amit J, Kumar P. Lung cancer in the Indian subcontinent. South Asian J Cancer 2017;5:95-103.

7. Bray F, Ferlay J, Soerjomataram I, Siegel RL, Torre LA, Jemal A. Global cancer statistics 2018: GLOBOCAN estimates of incidence and mortality worldwide for 36 cancers in 185 countries. Cancer J Clin 2018;68:394-424.

8. Thomas VD, Jose B, Rennis DK. Prevalence of type and aetiology of lung cancer among the patients presented to a tertiary care hospital at central Kerala: a descriptive study. Int J Res Med Sci 2018;6:834-7.

9. Jemal A, Bray F, Centre MM, Ferlay J, Ward E, Forman D. Global cancer statistics. CA Cancer J Clin 2011;61:69-90.

10. Xu Dong D, Chun Yan L, Xi Wen S, Yu Bo S, Ying Ji L. The aetiology of lung cancer in non-smoking females in Harbin, China. Lung Cancer 1996;14(Suppl 1):S85-S91.

11. Neal DF, Michael FL, Albert RH, Arthur S, Christian CA. Cigarette smoking and subsequent risk of lung cancer in men and women: analysis of a prospective cohort study. Lancet Oncol 2008;9:649-56.

12. Parikh PM, Ranade AA, Govind B, Ghadyalpatil N, Singh R, Bharat $\mathrm{R}$, et al. Lung cancer in India: current status and promising strategies. South Asian J Cancer 2017;5:93-5.
13. Behera D. Lung cancer in India: challenges and perspectives. J Thorac Oncol 2017;12(1S):S114-S115.

14. Reck M, Heigener DF, Mok T, Soria JC, Rabe KF. Management of non-small-cell lung cancer: recent developments. Lancet 2013;382:709-19.

15. Pamela V, Ignacio IW. Lung cancer biomarkers. Hematol Oncol Clin N Am 2017;31:13-29.

16. Bangash NSA, Hashim N, Ismail NE. Smoking status affecting survival of adenocarcinoma lung cancer patients in Kualalumpur, Malaysia. Asian J Pharm Clin Res 2017;10:312-3.

17. Jinfu H, Yang M, Dagny D, Kathy W. Risk factors for lung cancer among canadian women who have never smoked.Cancer Detection Prevention 2002;26:129-38.

18. Kevin H, Harry JK. Should never-smokers at increased risk for lung cancer be screened? J Thorac Oncol 2015;10:1285-91.

19. William JM, Rafael M, Jihyoun J, Sureshb M. Lung cancer in never smokers epidemiology and risk prediction models. Risk Anal 2012;32(Suppl 1):S69-S84.

20. Vidyullatha P. Lung cancer incidence in never smokers: genetic and gender basis. Gene Reports 2016;4:198-207.

21. Charles SD, Lynn TT, Richard AM. Lung cancer: epidemiology and prevention. Clin Chest Med 2011;32:1-61.

22. Sebastein C, Gerard Z, Bernard M, Franck M, Pierre-Jean S. Lung cancer in never smokers-a review. Eur J Cancer 2012;48:1299311.

23. Yang P. Lung cancer in never-smokers. Semin Respir Crit Care Med 2011;32:10-21.

24. Ole Raaschou Nielson. Air pollution: another cause of lung cancer. Lancet Oncol 2013;14:788-9.

25. Lim SS, Vos T, Flaxman AD, Danaei G, Shibuya K, Adair Rohani $\mathrm{H}$, et al. A comparative risk assessment of burden of disease and injury attributable to 67 risk factors and risk factors clusters in 21 regions, 1990-2010:a systematic analysis for the global burden of disease study. Lancet 2012;380:2224-60.

26. Greg AR, Mia H, Bhola S, Mei W, Binay KT, Chin BP, et al. Household air pollution and lung cancer risk among neversmokers in Nepal. Environ Res 2016;147:141-5.

27. William JM, Rafael M, Jihyoun J, Suresh M. Lung cancer in never smokers epidemiology and risk prediction models. Risk Anal 2012;32(Suppl 1):S69-S84.

28. Ying Xiu D, Qing C, Xiao Wei C, Yong Zhong C, Lan Fang H, Zhen Zhi $\mathrm{F}$, et al. An epidemiological study of risk factors for lung cancer in guan Gzhou, China. Lung Cancer 1996;14(Suppl 1):S9-S37.

29. Raaschou Nielson OR, Anderson ZJ, Hvidberg M, Jensen SS, Ketzel M, Sorensen $\mathrm{M}$, et al. Lung cancer incidence and longterm exposure to air pollution from traffic. Environ Health Perspect 2011;119:860-5.

30. Nyberg F, Gustavsson P, Jarup L, Bellander T, Berqlind N, Jakobsson $\mathrm{R}$, et al. Urban air pollution and lung cancer in Stockholm. Epidemiology 2000;11:487-95.

31. Madiha K, Xiao Ji D, Yi Cao. Familial risk for lung cancer. Oncol Lett 2017;13:535-42.

32. Elisabetta R, Surinder KJ, Dheeraj G, Paolo B. Passive smoking and lung cancer in Chandigarh, India. Lung Cancer 1999;23:183-9.

33. Hackshaw AK, Law MR, Wald NJ. The accumulated evidence on lung cancer and environmental tobacco smoke. Br Med J 1997;315:980-8.

34. Claire HK, Yuan Chin AL, Rayjean JH, Sheila RM, Michele LC, Wei Yen L, et al. Exposure to second-hand tobacco smoke and lung cancer by histological type: a pooled analysis of the International Lung Cancer Consortium (ILCCO). Int J Cancer 2014;135:1918-30.

35. National Toxicology Program. Asbestos, Department of Health and Human services report on carcinogens. 12th edition. 2011 Available from: http://ntp.niehs.nih.gov/ntp/roc/twelvth/ profiles/Asbestos.pdf. [Last accessed on 10 May 2018].

36. William RF, Brian LW. Occupational and environmental causes of lung cancer. Clin Chest Med 2012;33:681-703.

37. IARC Monographs on the evaluation of carcinogenic risks to humans. A review of human carcinogens: arsenic, metals, fibres, and dusts, arsenic and arsenic compounds. Vol 100C; 
2012. Available from: http://monographs.iarc.fr/ENG/ monographs/vol100C/mono100c-6.pdf. [Last accessed on 15 Apr 2018].

38. Clement Duchene C, Vignaud JM, Stoufflet A, Bertrand O, Gislard A, Theberville L, et al. Characteristics of never smoker lung cancer including environmental and occupational risk factors. Lung Cancer 2010;67:144-50.

39. IARC Monographs on the evaluation of carcinogenic risks to humans. Occupational exposure in the rubber industry. Vol. 100F; 2012. Available from: http://monographs.iarc.fr/ENG/ monographs/vol100F/mono100F-36.pdf. [Last accessed on 12 Apr 2018].

40. Pronk A, Coble J, Stewart PA. Occupational exposure to diesel exhaust: a literature review.J Expo Sci Environ Epidemiol 2009;19:443-57.

41. National Toxicology program. Report on carcinogens, coal tars and coal-tar pitches. $12^{\text {th }}$ edition. US Department of Health and Human services, Public Health Service; 2011. p. 111-3. Available from: http://ntp.niehs.nih.gov/ntp/roc/twelfth/ profiles/coaltars.pdf. [Last accessed 25 Apr 2018].

42. Pukkala E, Martinsen JI, Lynge E, Gunnarsdottir HK, Sparen P, Tryqqvadottir L, et al. Occupation and cancer-follow-up of 15 million people in five nordic countries. Acta Oncol 2009;48:646790.

43. HSDB. Hazardous substances data bank. National Library of medicine; 2012. Available from: http://toxnet.nlm.nih.gov/cgibin/sis/search/f/temp/zkjdFQ:1. [Last accessed 25 Apr 2018]

44. Lingling $\mathrm{L}$, Tianhai $\mathrm{T}$, Xinan $\mathrm{Z}$. The impact of radiation the development of lung cancer. J Theor Biol 2017;428:147-52.

45. Hendee WR. Estimation of radiation risks: BEIR V and its significance for medicine. JAMA 1992;268:620-4.

46. EI Ghissassi F, Baan R, Straif K, Grosse Y, Secretan B, Bouvard B, et al. A review of human carcinogens--part D: radiation. Lancet Oncol 2009;10:751-2.

47. Field RW. Radon: an overview of health effects. In: Nriagu Jo. editor. Encyclopaedia of environmental health. Vol. 4. Burlington (Ontario): Elsevier; 2011. p. 745-53.

48. Tokuhata GK, Lilienfeld. Familial aggregation of lung cancer among hospital patients. Public Health Rep 1963;78:277-84.

49. Classidy A, Myles JP, Duffy SW, Liloglou T, Field JK. Family history and risk of lung cancer: age-at-diagnosis in cases and first degree relatives. Br J Cancer 2006;95:1288-90.

50. Elizabeth M, Gaughan, Sarah KC, Beow YY, David MJ, Daniel BC Family history of lung cancer in never smokers with non-small cell lung cancer and its association with tumor sharboring EGFR mutations. Lung Cancer 2013;79:193-7.

51. Cote ML, Liu M, Bonassi S, Neri M, Schwartz AG, Christiani DC, et al. A randomized phase II trial of S-1-oxaliplatin versus capecitabine-oxaliplatin in advanced gastric cancer. Eur J Cancer 2012;48:1957-6.

52. Virginia LE. The epidemiology of lung cancer in women. Ann Epidemiol 1994:4:102-10.

53. Darren RB, Paolo B, Eric JD, Heike B, Albert R, Valerie M, et al. Previous lung diseases and lung cancer risk: a pooled analysis of the International lung cancer consortium. Am J Epidemiol 2012;176:573-85.

54. Azad N, Rojanasakul Y, Vallyathan V. Inflammation and lung cancer: roles of reactive oxygen/nitrogen species. J Toxicol Environ Health B Crit Rev 2008;11:1-15.
55. Kostas A, Paschalis S, Argyris T, Evangelia N, Demosthenes B. Lung cancer and interstitial lung diseases: a systematic review. Pulm Med 2012;2012:1-11.

56. Schwartz AG, Cote ML, Wenzlaff AS, Vandyke A, Chen W, Ruckdeschel JC, et al. Chronic obstructive lung disease and risk of non-small cell lung cancer in women. J Thorac Oncol 2009;4:291-9.

57. Darren BR, John RM, Rayjean JH. Previous lung diseases and lung cancer risk: a systematic review and meta-analysis. PloS One 2011;6:1-10.

58. Barnes PJ, Adcock IM. Chronic obstructive pulmonary disease and lung cancer: a lethal association. Am J Respir Crit Care Med 2011;184:866-7.

59. Menck H, Hnederson BE. Cancer incidence patterns in the pacific basin. Nat Cancer Mongr 1982;62:101-9.

60. Cote ML, Kardia SL, Wenzlaff AS, Ruckdeschel JC, Schwartz AG. Risk of lung cancer among white and black relatives of individuals with early-onset lung cancer. JAMA 2005;293:3036-42.

61. Wynder EL, Graham EA. Tobacco smoking as a possible etiologic factor in bronchiogenic carcinoma: a study of 684 proved cases. J Am Med Assoc 1950;143:329-36.

62. Slegel R, Ward E, Brawley O. Cancer statistics, the impact of eliminating socioeconomic and racial disparities on premature cancer deaths. CA cancer J Clin 2011;61:212-36.

63. Hugo DP, Eduardo DS, Alvaro R, Maria M, Julio CC. Meat consumption and risk of lung cancer; a case-control study from Uruguay. Lung Cancer 1996;14:195-205.

64. Behera D, Balamugesh T. Lung cancer in India. Ind J Chest Dis Allied Sci 2004;46:269-81.

65. Sankaranarayanan R, Varghese C, Dugffy SW, Padmakumary G, Day NE, Nair MK. A case-control study of diet and lung cancer in Kerala, South India. Int J Cancer 1994:58:644-9.

66. Brennan P, Hsu CC, Moullan N, Szeszenia-Dabrowska N, Lissowska J, Zaridze D, et al. Effect of cruciferous vegetables on lung cancer in patients stratified by genetic status: a mendelian randomisation approach. Lancet 2005;366:1558-60.

67. Cooper DA, Eldridge AL, Peters JC. Dietary carotenoids and lung cancer: a review of recent research. Nutr Rev 1999;57:133-45.

68. Sanskruti S, Anshika NS, Sharma N. Potential anti-cancer super foods: a mini review. Int J Curr Pharm Res 2016;8:19-21.

69. Mostafa H, Parisa AN, Ali MJ, Mahmoud Y, Shervin T, Kian K, et al. Nutrition and lung cancer: a case control study in Iran. BMC Cancer 2014:14:1-9.

70. Sugimura T, Wakabayashi K, Nagao M, Ohgaki H. Mutagens and carcinogens formed during cooking. In: Caroll KK. editor. Diet, nutrition and health. Montreal and Kingston: McGill-Queens University Press; 1989. p. 207-28.

71. Mazahar F, Rajendra P, Santosh J. Antioxidant-vitamin c: lung function; lung cancer. Asian J Pharm Clin Res 2016;9)Suppl 2):43-51.

72. Ping Yang. Lung cancer in never smokers. Semin Respir Crit Care Med 2011:32:10-21.

73. Gregory DK, Christian AM. HIV infection in the etiology of lung cancer: confounding, causality, and consequences. Proc Am Thorac Soc 2011;8:326-32.

74. Hinds MW, Cohen HI, Kolonel LN. Tuberculosis and lung cancer risk in non-smoking women. Am Rev Respir Dis 1982;125:776-8.

75. Littman AJ, Jackson LA, Vaughan TL. Chlamydia pneumonia and lung cancer: epidemiologic evidence.Cancer Epidemiol Biomarkers Prev 2005;14:773-8. 